OPEN ACCESS

Edited by:

Javier Egea

Princess University Hospital, Spain

Reviewed by:

Águeda González Rodríguez,

Princess University Hospital, Spain

Jing Yuan,

Children's Hospital of Capital Institute

of Pediatrics, China

Xiaojie Xu,

Beijing Institute of Technology, China

${ }^{*}$ Correspondence:

Juqiang Han

hanjuqiang2014@126.com

Specialty section

This article was submitted to

Gastroenterology,

a section of the journal

Frontiers in Medicine

Received: 14 January 2021

Accepted: 07 July 2021

Published: 29 July 2021

Citation:

Han J and Zhang X (2021)

Complement Component C3: A Novel

Biomarker Participating in the

Pathogenesis of Non-alcoholic Fatty

Liver Disease. Front. Med. 8:653293.

doi: 10.3389/fmed.2021.653293

\section{Complement Component C3: A Novel Biomarker Participating in the Pathogenesis of Non-alcoholic Fatty Liver Disease}

\author{
Juqiang Han ${ }^{1,2 *}$ and Xiang Zhang ${ }^{2}$ \\ ${ }^{1}$ Institute of Liver Disease, The 7th Medical Centre of Chinese People Liberation Army General Hospital, Beijing, China, ${ }^{2}$ The \\ Department of Medicine and Therapeutics, State Key Laboratory of Digestive Disease, Institute of Digestive Disease, Li Ka \\ Shing Institute of Health Sciences, Chinese University of Hong Kong Shenzhen Research Institute, The Chinese University of \\ Hong Kong, Hong Kong, China
}

Non-alcoholic fatty liver disease (NAFLD) is currently the most common cause of chronic liver disorder worldwide. The pathological spectrum of NAFLD ranges from simple steatosis to non-alcoholic steatohepatitis (NASH) that induces progressive liver cirrhosis and eventually hepatocellular carcinoma (HCC). However, the molecular mechanisms driving the transformation of $\mathrm{NASH}$ are obscure. There is a compelling need for understanding the pathogenic mechanisms of $\mathrm{NASH}$, and thereby providing new insight into mechanism-based therapy. Currently, several studies reported that complement system, an innate immune system, played an important role in the pathogenesis of NAFLD, which was also proved by our recent study. Complement component 3 (C3), a protein of the innate immune system, plays a hub role in the complement system. Herein, we present a review on the role and molecular mechanism of C3 in NASH as well as its implication in NASH diagnosis and treatment.

Keywords: non-alcoholic fatty liver disease, complement C3, complement C3 receptor, pathogenic mechanism, therapy

\section{INTRODUCTION}

Non-alcoholic fatty liver disease (NAFLD) has become a very common liver disease worldwide. The disease spectrum includes non-alcoholic fatty liver (NAFL), non-alcoholic steatohepatitis(NASH), nutritional fibrosis and hepatocellular carcinoma Cancer (HCC). Epidemiological investigations show that the prevalence of NAFLD is $25-30 \%$ in western countries (1). With the change of diet structure and lifestyle, the prevalence of NAFLD is $17-46 \%$ in China (2). Notably, the prevalence of NAFLD in young children is currently increasing year by year, and the high prevalence rate is alarming (3). Among NAFLD patients, the prevalence of NASH is about $20 \%$ (4). However, the diagnosis of NASH relies on liver biopsy and the non-invasive diagnostic methods are limited. To date, there's no Food and Drug Administration (FDA)-approved drug for NAFLD and NASH treatment. Therefore, there is an unmet clinical need for the diagnosis, prevention and treatment of NAFLD and NASH. In recent years, innate immunity is thought to play an important role in the development of NAFLD. Therefore, we summarized previous studies and provided a holistic framework concerning the relationship between complement and NAFLD. 


\section{THE OVERVIEW OF COMPLEMENTS SYSTEM}

In the early stage of NAFLD, bacterial endotoxin, free fatty acid (FFA), cholesterol and many other substances in the body can activate the complement system through danger associated molecular patterns (DAMPs) or pathogen associated molecular pattern (PAMPs) $(5,6)$. Complement system, which is considered as an important innate immunity (7-10), has been confirmed to be cascade-activated through the following three pathways: classical, lectin and alternative, all of which converge in the formation of fraction C3. Briefly, in the activated complement signaling pathway, complement component $\mathrm{C} 3$ is cleaved into $\mathrm{C} 3 \mathrm{a}$ and $\mathrm{C} 3 \mathrm{~b}$ through $\mathrm{C} 3$ converting enzyme, in which $\mathrm{C} 3 \mathrm{~b}$ binds with $\mathrm{C} 3$ converting enzyme complex to form $\mathrm{C} 4 \mathrm{bC} 2 \mathrm{aC} 3 \mathrm{~b}$ complex in classical pathway and lectin pathway and $\mathrm{C} 3 \mathrm{bBbC} 3 \mathrm{~b}$ complex in alternative pathway. Both complexes are converting enzymes of complement molecule $\mathrm{C} 5$, and then further activate the downstream molecules of Complement system to form membrane attack complex (MAC/C5b-9). Furthermore, the classical activation pathway mainly involves the binding of antigen with immunoglobulin (IgM or IgG) or C-reactive protein. In the lectin pathway, Complement activation is triggered by the interaction complex carbohydrate residues with the surface of pathogens to circulating mannose binding lectins (MBL) or ficolins. The alternative pathway is activated by the direct combination of hydrolyzed $\mathrm{C} 3 \mathrm{~b}$ and bacterial membrane surface (Figure 1).

\section{COMPLEMENT C3 AND NAFLD}

Currently, the role of Complement system in NAFLD disorders has been extensively investigated in clinical epidemiological studies (11). Serum complement C3 levels are positively associated with the severity of NAFLD. A Turkish case-control study involving 46 NAFLD patients demonstrated that the level of Complement component C3 was significantly higher in peripheral blood of NAFLD patients than that of healthy control group and chronic hepatitis B control group (12). Moreover, a Dutch cross-sectional study involving 523 middle-aged and elderly patients with NAFLD found that the level of C3a, the active product of complement $\mathrm{C} 3$, was closely related to liver fat content (13). Consistently, two large sample epidemiological studies recruited thousands of cases in China showed that the level of serum complement C3 was an independent risk factor for the diagnosis of NAFLD and related to the prevalence and the severity of NAFLD $(14,15)$. Apart from the serum, the deposition of $\mathrm{C} 3$ is also identified in the liver tissue of NAFLD patients accompanied with the deposition of MACC9 (16). The deposition of C3 was proved to be mainly

\footnotetext{
Abbreviations: NAFLD, Non-alcoholic fatty liver disease; NASH, Non-alcoholic steatohepatitis; HCC, hepatocellular carcinoma; C3, Complement component 3; NAFL, non-alcoholic fatty liver; FDA, Food and Drug Administration; FFA, free fatty acid; DAMPs, danger associated molecular patterns; PAMPs, pathogen associated molecular patterns; MAC, membrane attack complex; MBL, mannosebinding lectin; IL, interleukin; KCs, Kupffer cells; NLR, neutrophil to lymphocyte ratio; NAS, NAFLD activity score.
}

located around the hepatocytes with macrovesicular steatosis. Subsequently, clinicopathological examination confirmed that a large number of hepatic parenchymal cells were apoptotic in the liver tissue with complement $\mathrm{C} 3$ activation. Complement C3 activation could lead to a large number of neutrophils infiltration and abnormal increase of IL- 8 and IL-6 expression in liver tissue, while C9 deposition could lead to increased IL$1 \beta$ expression in liver cells. Additionally, in other patients with NAFLD, there was a close correlation between serum C3 level and NAFLD. For example, Pan et al. demonstrated that C3 was the only highly predictive factor in diagnosing NAFLD from 648 recruited patients with chronic kidney disease by Logistic regression analysis (17). Ursini et al. recruited 164 patients with rheumatoid arthritis, of which 25\% (41/164) were complicated with NAFLD. Further logistic regression analysis also confirmed the high correlation between C3 and NAFLD analysis (18). Most importantly, Himoto et al. found that the increased serum C3 levels are closely related to the abnormal metabolism of the body including obesity, insulin resistance, and/or hepatic steatosis in those patients with chronic hepatitis C, which had nothing to do with chronic HCV infection (19). Collectively, the complement system is closely related to NAFLD. It is speculated that the complement system is largely activated to regulate the immune inflammatory response in the pathogenesis of NAFLD, which directly participates in the occurrence, development and prognosis of NAFLD.

\section{THE PATHOGENIC C3 ACTIVATION IN NAFLD PROGRESSION}

NAFLD severity was closely associated with accumulation of activation products of $\mathrm{C} 3$ around steatotic hepatocytes. However, the underlying mechanism by which complement $\mathrm{C} 3$ in NAFLD remained elusive. Hepatocytes are confirmed to be the predominant origin of complement components including C3 protein. Because C3 is the key molecule in the pathway of complement system activation (7), several hypotheses are proposed that $\mathrm{C} 3$ plays an important role in lipid metabolism in the pathogenesis of NAFLD (Figure 2): Firstly, C3 is mainly synthesized by hepatocytes and identified to appear in lipoprotein particles such as high density lipoprotein and chylomicron (20, 21). When complement C3 gene was knocked out in mice, serum triglyceride levels increased 58\% higher compared with wild-type mice, and the increased lipoprotein profile is mainly low-density lipoprotein and very low-density lipoprotein (21), indicating a potential role of C3 in lipid metabolism regulation (22). Secondly, Complement system directly regulates the oxidative stress in hepatocytes with excessive fat accumulation. It is well-known that multiple-hit hypothesis has been widely accepted in the pathogenesis of NAFLD. The first hit is closely linked with insulin resistance under fat accumulation. With the response of hepatocytes to oxidative stress, a large number of inflammatory cytokines are secreted in the liver, which further cause the second hit in hepatocytes (23). Complement component C3, as a major player in innate immune response, might be activated by the first hit and forming the second hit in NAFLD 


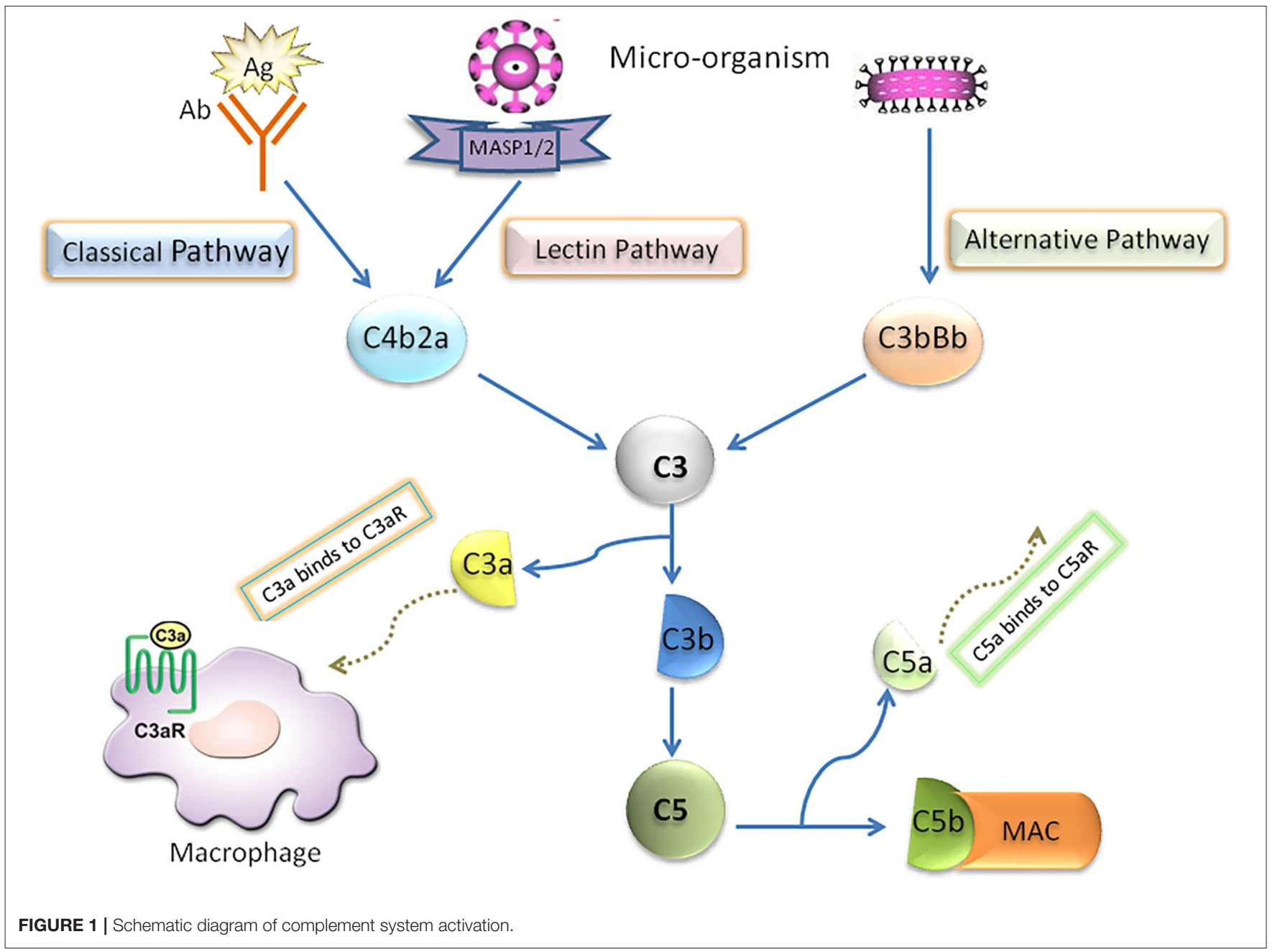

pathogenesis (24). Thirdly, the phenomenon of apoptosis is a typical pathological feature in the liver with NAFL and NASH. Due to the accumulated fat droplets in hepatocytes, a variety of apoptotic cascade pathways are activated including caspases 3 and 7 or cleavage of cytokeratin 18, resulting in a large number of hepatocytes apoptosis. Complement system was found to be quickly activated by the apoptotic hepatocyte debris. Furthermore, the activated Complement system immediately recognized and cleaned the apoptotic pathological liver cells, thus maintaining the homostasis in liver (25). Thus, elevation of serum complement $\mathrm{C} 3$ might act as a protective response in NAFLD mediated by apoptosis. Finally, Complement activation is indicated to be involved of novel molecular mechanism in the pathogenesis of NAFLD. Acylation-stimulating protein (ASP), a C3 derivative involved in adipocyte lipid metabolism by stimulating triglyceride synthesis, was reported to be increased in NAFLD patients (26). A vicious cycle has been further confirmed in the pathogenesis of NAFLD. ASP can promote the fat accumulation in liver cells to exacerbates hepatic steatosis. On the other hand, the fatty liver promotes the activation of complement system to increase ASP synthesis (12). In brief, there is a potential balance in the pathogenesis of NAFLD between complement system activation and hepatocyte lipid metabolism signaling, which maintains the stability of liver internal environment. Once the balance is broken, the process of hepatocyte lipid metabolism will enter a vicious circle, which exacerbates irreversibly hepatic steatosis as a consequence.

\section{C3a/C3aR ACTIVATION AND METABOLIC FUNCTION}

Recently, increased evidence showed that C3a can change the storage, transportation and utilization of glycolipids in adipocytes and directly affect adipogenesis, glucose uptake and lipolysis in the pathogenesis of NAFLD. Oral administration of selective C3aR antagonist for 8 weeks can significantly improve the typical symptoms of metabolic syndrome in dietinduced obese rats, including weight loss, visceral fat reduction, glucose and insulin intolerance improvement, adipose tissue inflammation relief, blood lipid concentration dropping, etc. The above research results innovatively provide two novel mechanisms of C3a involved in energy metabolism on theoretical and experimental basis, that is, C3a can not only promote 


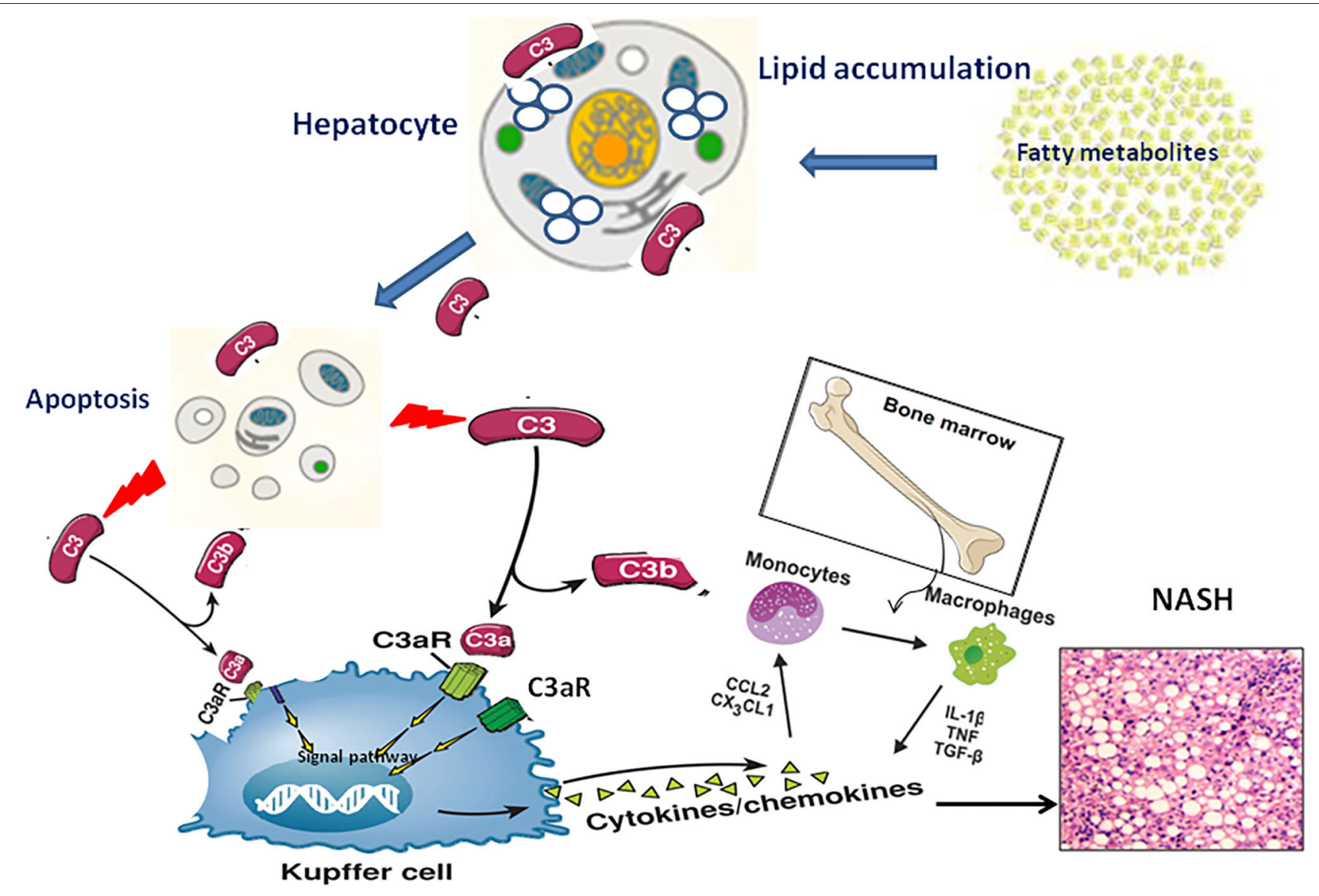

FIGURE 2 | The pathogenic mechanism of C3 activation in NAFLD progression through lipid accumulation, immune response and apoptosis.

the uptake of fatty acids and glucose by adipocytes, but also inhibit fat burn-off by inhibiting cAMP synthesis and lipolysis in adipocytes (27). These studies fully elucidate the important correlation between complement $\mathrm{C} 3 \mathrm{a} / \mathrm{C} 3 \mathrm{aR}$ signaling pathway and energetic metabolism, and further reveal the molecular mechanism of abnormal immune response aggravating obesity and metabolic dysfunction. More importantly, antagonists targeting $\mathrm{C} 3 \mathrm{a} / \mathrm{C} 3 \mathrm{aR}$ signaling pathway is considered as a novel strategy for the treatment of metabolic dysfunction, including NAFLD. Consistently, our recent result also found that C3a/C3aR signal pathway was closely related to the development of $\mathrm{NASH}$-fibrosis. In $\mathrm{C}_{3} \mathrm{aR}^{-1-}$ mice model, we also demonstrated that $\mathrm{C} 3 \mathrm{aR}$ depletion significantly reduced the progression of NASH related liver fibrosis (28).Studies have confirmed that $\mathrm{C} 3 \mathrm{a}$ is an important derivative produced by $\mathrm{C} 3$ cleavage when complement system is activated. C3a has significant biological characteristics of anaphylactic toxin and is an important proinflammatory molecule in the body. It can directly trigger mast cells degranulation, inflammatory reaction, chemotaxis effect, granulocyte activation as well increasing vascular permeability, promoting smooth muscle contraction and clearing away the immune complexes, etc (29). In other words, C3a plays an important role in the pathogenesis of a variety of clinical diseases, including organ ischemia-reperfusion injury, sepsis and metabolic inflammation (27, 30-37). Structurally, C3a is composed of 77-aa polypeptide containing three to four helical regions. A series of irregular amino acid residues is also proved in the C-terminal of C3a protein, which is flexible in spatial conformation. There is evidence that these flexible C-terminal residues are necessary to stabilize the conformation on binding C3aR by the upstream a helix (38-40). It has been demonstrated that $\mathrm{C} 3 \mathrm{a}$ exerts its biological effect mainly by binding to its receptor $\mathrm{C} 3 \mathrm{aR}$, which belongs to $\mathrm{G}$ protein-coupled receptor containing seven trans-membrane regions. C3a/C3aR interaction is generally regulated by $\mathrm{G}$ protein-coupled receptor kinasemediated receptor phosphorylation (41). In the past, it has been considered that C3aR is the only specific receptor of C3a. It shares close homology with $\mathrm{C} 5 \mathrm{a}$ specific receptors C5aR1 and $\mathrm{C} 5 \mathrm{aR} 2$. However, recent studies have showed that the interaction of $\mathrm{C} 3 \mathrm{a} / \mathrm{C} 3 \mathrm{aR}$ seems to be more complex than expected. For example, C3aR has been found to be able to couple with heterotrimeric $\mathrm{G}$ proteins depending on different cell types (4244). In human granulocytes, C5a can inhibit the activity of C3aR. Ruan et al. confirmed that C3a can form a complex with $\mathrm{CpG}$ oligonucleotides to improve the release of IFN-a in monocytes (45). Neuropeptide TLQP-21 (a cleaved fragment 
of VGL propeptide) was found to specifically binds on C3aR and fully activate the biological function of $\mathrm{C} 3 \mathrm{aR}$ in mice, which completely comply with the conformational change of ligand/receptor interaction $(46,47)$. Additionally, recent studies have demonstrated that $\mathrm{C} 3 \mathrm{a}$ can bind to the receptor of advanced glycation end products (RAGE) with very high affinity, but this high affinity interaction cannot be explained by a simple ligand upon receptor binding $(45,48)$.

\section{C3a/C3aR AXIS AND IMMUNE RESPONSE IN NAFLD}

\section{Kupffer Cells/Macrophages and C3a/C3aR Axis in NAFLD}

Liver is the largest reservoir of macrophages in the body, and macrophages in liver play a key role in the pathogenesis of NAFLD $(23,49,50)$. According to different origin, macrophages in liver can be divided into two types, one is Kupffer cells fixed in liver, the other is monocytes/macrophages derived from bone marrow. They mainly play the role of innate immunity such as phagocytosis and secretion of inflammatory cytokines. At the early stage of NAFLD, Kupffer/macrophage cells are the first defense lines against the accumulation of excessive lipid metabolites in the liver. Firstly, steatotic hepatocytes disturb hepatic sinusoidal perfusion because of the "gap occupying" effect and Kupffer cells are subsequently attracted by neutrophils to the sinusoidal gap to participate inflammation. Secondly, free fatty acids (FFA) excessively interact with the FFA specific receptors on Kupffer/macrophage cells surface to regulate inflammatory response. Thirdly, Kupffer/macrophage cells mistakenly attribute the abnormal hepatocytes full of excessive lipid accumulation to the harmful substances and immediately phagocytize and destroy them, which further aggravate hepatocyte damage (51). Under the above conditions, these overactivated Kupffer/macrophage cells secrete a large number of inflammatory cytokines (such as TNF $\alpha, \mathrm{IL}-6, \mathrm{IL}-1 \beta$ ) as well as inflammatory chemokines (such as CCL2, CCL3, CCL5, CXCL16, CX3CL1,). In addition, Kupffer cells also recruit a large number of bone marrow-derived monocytes/macrophages into the liver to expand the inflammatory response and accelerate the liver from simple steatosis to NASH (52). CCL2/CCR2 interaction is proved to be the first signal pathway in Kupffer/macrophage recruiting monocytes from bone marrow (53). Afterwards, some other chemokines signal pathways are also confirmed through Kuppfer cells mechanisms such as CXCL10/CXCR3, CCL5/CCR1, and CCL1/CCR8 (11). In recent years, a number of research groups have got the highly consistent results by various ways to delete macrophages in NAFLD mice model (54-56). Namely, knocking-out monocytes/macrophages can reduce significantly the severity of liver steatosis and inflammation and further delay the process of NAFLD. However, so far, there is no systematic and in-depth study on the specific molecular mechanism of regulating macrophage activation in the whole pathogenesis of NAFLD.

As mentioned above, hepatocytes are the main origin to synthesize C3a molecules, and C3aR is predominantly located in the cell membrane of monocytes/macrophages. In the chronic phase of liver inflammation, $\mathrm{C} 3 \mathrm{a} / \mathrm{C} 3 \mathrm{aR}$ signaling activity is showed more significant in monocytes/macrophages than that of neutrophils $(57,58)$. Under this condition, C3a can activate the signal pathway of peripheral blood monocytes with the co-stimulation of TLR-4, and further induce the secretion of various proinflammatory factors such as IL- $1 \beta$, TNF- $\alpha$, IL-6 and PGE2 (59-63). This view is supported by evidence that liver steatosis have modest pathology reductions in $\mathrm{C} 3 \mathrm{aR} 1^{-/-}$mice models (57). Therefore, we speculate that the $\mathrm{C} 3 \mathrm{a} / \mathrm{C} 3 \mathrm{aR}$ interaction may be a novel signaling pathway by activating macrophages to regulate the occurrence and development of NAFLD. In the early stage of NAFLD, a large amount of fat accumulates in hepatocytes, resulting in the broken balance between complement system activation and hepatocyte lipid metabolism. Subsequently, Complement cascades enter into an overactivated state and excessive amount of C3 molecular is cleaved to release C3a. Through the specific interaction of $\mathrm{C} 3 \mathrm{a} / \mathrm{C} 3 \mathrm{aR}$, Kupffer/macrophages cells in the liver are directly activated to secrete inflammatory chemokines to recruit monocytes from peripheral blood into the liver, which further expand the inflammatory response in the steatotic liver (24) (Figure 2).

\section{Hepatic Stellate Cell and C3a/C3aR Axis in NAFLD}

Under normal physiological conditions, component C3 is mainly expressed in hepatic parenchymal cells. However, recent evidence has demonstrated that C3 is also slightly expressed in other type cells such as bone marrow cells, lymphocytes, fibroblasts and endothelial like cells (64). Activated hepatic stellate cells, as the initiating factor of hepatic fibrogenesis, have obvious characteristics of fibroblasts. Up to now, there are relatively few reports about complement C3 directly involved in the activation of hepatic stellate cells (HSCs) about NAFLD. A recent study showed that activated hepatic stellate cells could promote the hepatocarcinogenesis through $\mathrm{C} 3$ signaling pathway by inhibiting the proliferation of CD $4+$ and CD8 + cells, promoting the exhausting anti-tumor $\mathrm{T}$ lymphocytes as well as improving the differentiation of bone marrow-derived suppressor cells (MDSC) (65). Consistently, our recent results demonstrated that $\mathrm{C} 3 \mathrm{a} / \mathrm{C} 3 \mathrm{aR}$ signaling pathway was activated in the mouse model of nutritional fibrosis. The related mechanism is being further explored in $\mathrm{C}_{3} \mathrm{aR}^{-/-}$mice (28). However, Component cascade activated C5 molecular is found to be a key factor that contributes to hepatic fibrosisgenesis by enhancing the migration ability of hepatic stellate cells. Furthermore, the $\mathrm{C} 5 \mathrm{a} / \mathrm{C} 5 \mathrm{aR}$ axis was shown to directly mediate inflammatory, chemotactic and anaphylatoxic properties in innate and adaptive immunity as well as to modulate activation and migration of HSCs (66).

\section{T Cell and C3a/C3aR Axis in NAFLD}

It has been confirmed that $\mathrm{T}$ cells play an important regulatory role in the pathogenesis of NAFLD. The balance has a directly effect in the pathogenesis of NAFLD between Th1-secreted proinflammatory cytokines and Th2-secreted anti-inflammatory 
cytokines (67). The number of $\mathrm{CD}^{+}$helper $\mathrm{T}$ cell 17 (Th17) subsets was significantly higher than that of regulatory $\mathrm{T}$ cells (Treg) in the pathogenesis of NAFLD (68-72). With the development from simple steatosis to NASH, the number of Th17 cells in liver and peripheral blood increased continuously in a clinical epidemiological study of 104 human subjects (including 30 patients with NASH, 31 patients with simple steatosis and 43 healthy controls), resulting in a significant increase in Th17/resting $\mathrm{T}$ regulatory cell ratio (70). There is no doubt that $\mathrm{C} 3 \mathrm{a}$ molecule directly participates in $\mathrm{T}$ cells proliferation and differentiation as well as regulates the biological function, but the mechanism is complex $(73,74)$. It is still controversial whether $\mathrm{C} 3 \mathrm{aR}$ is widely expressed in $\mathrm{T}$ cells (75). When $\mathrm{C} 3 \mathrm{aR}$ gene was knocked-out as a target, the number of $\mathrm{T}$ cells was significantly reduced in $\mathrm{C}_{3} \mathrm{aR}^{-/-}$mice model $(73,76)$. Further studies confirmed that increasing the intracellular expression of C3a in T cells can significantly prolong their survival $(77,78)$. TCR stimulation can significantly up-regulate the expression of C3aR mRNA in T cells (79). Therefore, it is speculated that $\mathrm{C} 3 \mathrm{a}$ further regulates $\mathrm{T}$ cells proliferation, differentiation and biological functions through a potential autocrine way. Recent studies have shown that $\mathrm{C} 3 \mathrm{a}$ can promote $\mathrm{T}$ cell proliferation, enhance $\mathrm{T}$ cell reaction and prolong inflammatory response by inhibiting Treg production $(73,76)$. After adoptive transfer of $\mathrm{C}_{3} \mathrm{aR}^{-/-} \mathrm{T}$ cells into wild-type animals, the immunological function of Treg was seriously changed (76). In addition, there is evidence that $\mathrm{C} 3 \mathrm{aR}$ activation in antigen-presenting cells (APCs) can inhibit Th2 polarization and further block IL-4 secretion (80). Under the synergistic effect of C5aR1 signaling pathway, C3aR can suppress the production of TGF $-\beta 1$ by dendritic cells, reduce the stimulation of Treg differentiation, and then eliminate the inhibitory response to Th1 (76).

\section{Neutrophil and C3a/C3aR Axis in NAFLD}

Neutrophil infiltration is usually observed in the liver of NAFLD patients, and the severity of infiltration is closely related to disease progression $(81,82)$. The excessive fat accumulation overloads the normal metabolic capacity of hepatocytes. Subsequently, the abnormal metabolic injury results in neutrophils to be overactivated and recruited to the steatosic liver. After administration the neutrophil-specific antibody $1 \mathrm{~A} 8$ into mice, hepatic lipid accumulation and inflammation were significantly attenuated in HFD diet induced NAFLD models, which further slowed down the progress of NASH (83). Currently, neutrophil to lymphocyte ratio (NLR) has been clinically used as an effective biomarker to predict the severity of NAFLD (84-86). Accumulating evidence shows that NLR is positively correlated with NAFLD activity score (NAS) and an independent predictor of NAFLD prognosis. The higher the NLR value, the higher the severity of the disease, and the worse the prognosis of NAFLD. In the study of $101 \mathrm{NASH}$ patients, the NLR value was significantly higher than that of controls without NAFLD (mean 2.5 vs. $1.6, P<0.001$ ) (87). In the stage of $\mathrm{NASH}$ related fibrosis, the NLR value in advanced fibrosis stage (f3-4) was significantly higher than that of patients with early fibrosis stage (f1-2) (median: 2.9 and 1.8, $P<0.001$ ) (87). So far, it has been controversial for $\mathrm{C} 3 \mathrm{a} / \mathrm{C} 3 \mathrm{aR}$ interaction in neutrophils because the pure neutrophils was isolated difficultly over a long period in the past, which resulted in the doubt that $\mathrm{C} 3 \mathrm{a}$ induced neutrophil activation may be contaminated by non-neutrophils (88). At present, $\mathrm{C} 3 \mathrm{aR}$ is definitely identified to express with high level on the surface of neutrophils. Curiously, although $\mathrm{C} 3 \mathrm{a} / \mathrm{C} 3 \mathrm{aR}$ interaction can activate downstream ERK1/2/Akt signaling pathway, C3a alone does not play chemotactic function as well as stimulate neutrophil degranulation. Recent study suggested that the signaling produced by C3a stimulation of neutrophils was found to be dependent under the synergistic effect of C5aR2 (89). Another study demonstrated that C3a directly prevents neutrophils migration from bone marrow to peripheral circulation by antagonizing neutrophils migration factors (such as G-CSF) (72). Altogether, the specific mechanism of $\mathrm{C} 3 \mathrm{a} / \mathrm{C} 3 \mathrm{aR}$ in neutrophils in the pathogenesis of NAFLD needs to further explore in the coming future.

\section{C3a AS A BIOMARKER FOR NON-INVASIVE NASH DIAGNOSIS}

Although NASH is increasingly prevalent, it's hard to be diagnosed. Yet liver biopsy is recognized as the gold standard, but it is limited by its sampling bias, poor acceptability, and severe complications. Therefore, non-invasive methods are urgently needed to avoid biopsy for diagnosing NAFLD. Currently, some serum biomarkers have been widely accepted for the diagnosis of NASH such as the circulating serum levels of CK-18, the single nucleotide polymorphisms located in PNPLA3 as well as the non-coding RNAs, etc. (90). Especially, the most recent efforts concentrating on "omics" approaches (lipidomics, proteomics, and metabolomics) using high-throughput technologies have shown promising results to identify novel biomarkers of NAFLD, $\mathrm{NASH}$, and advanced fibrosis (91). However, those diagnostic accuracy need to be further improved by combining other different approaches.

Complement system activation has been demonstrated in liver biopsies from patients with NAFLD compared to healthy controls. It has been confirmed that complement C3 levels increased in patients with NASH, but not in those with viral liver disease. More recently, circulating C3 levels have been demonstrated to predict the presence of NAFLD in a large cohort from general population independently of the most plausible confounders such as the presence of metabolic syndrome and obesity. In addition, some similar evidence was also confirmed in the other disease combined with NAFLD. Ursini et al. provide an important evidence for the potential role of complement C3 as a surrogate biomarker of NAFLD in a large cohort of Rheumatoid arthritis (RA) patients at the best cut-off value of $1.23 \mathrm{~g} / \mathrm{l}$ for complement C3 with a sensitivity of $76 \%$ and a specificity of $64 \%$ (18). Pan et al. demonstrated the predictive role of complement $\mathrm{C} 3$ as a candidate biomarker for diagnosing NAFLD in chronic kidney disease (CKD) patients at the best cutoff value of $993.5 \mathrm{mg} / \mathrm{L}$ for complement C3 with a sensitivity of $63.9 \%$ and a specificity of $70.1 \%$ (17). Therefore, serum C3 may be fully used as a non-invasive diagnostic marker in the coming clinical diagnosis of NASH. 


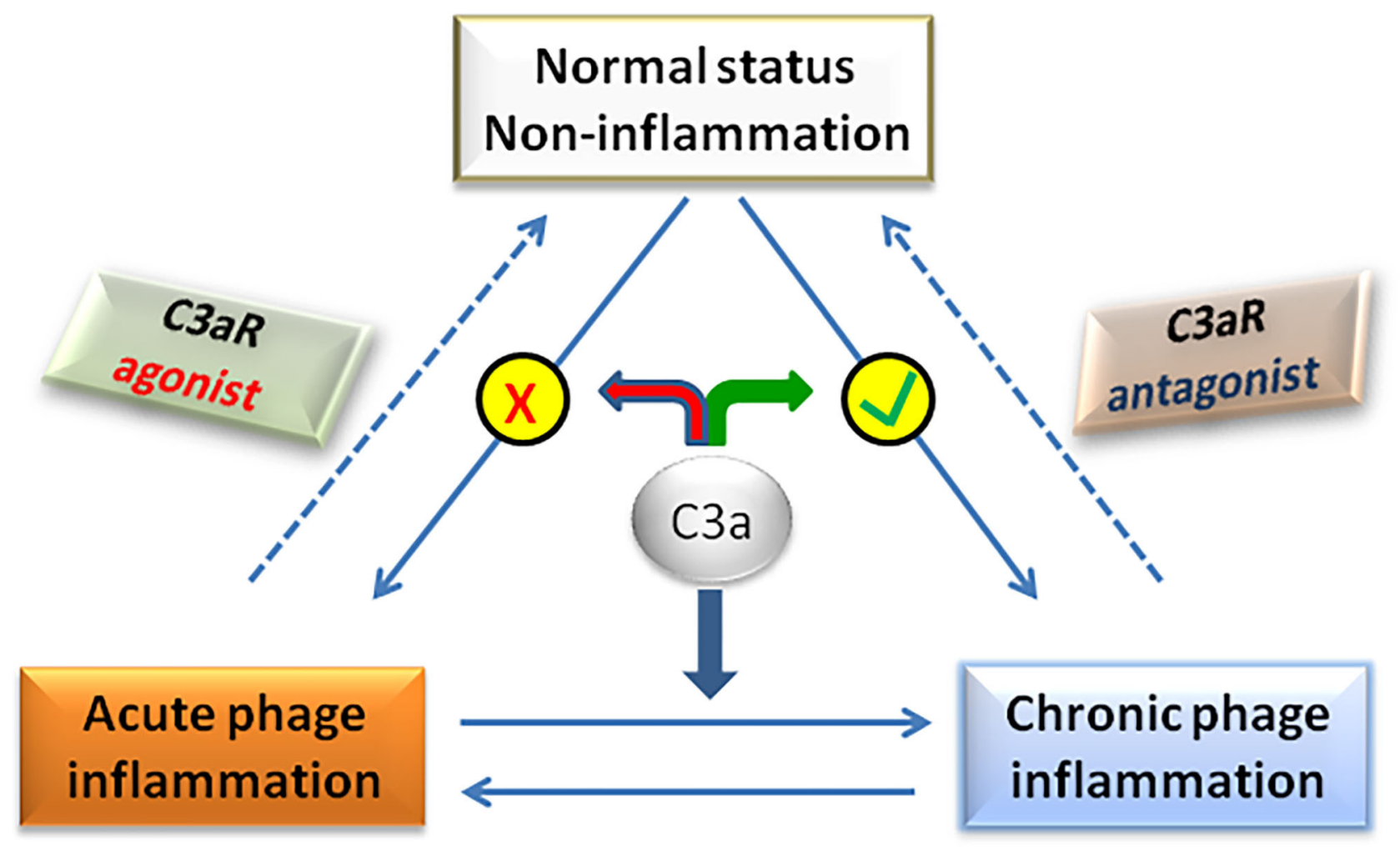

FIGURE 3 | The balance of C3a actions determines the disease phenotype.

\section{THE POTENTIAL BENEFIT FROM ANTAGONIZING C3aR IN NASH THERAPY}

With the increasing incidence of global NAFLD, more and more strategies are explored to prevent effectively NASH in medical treatment nowadays. It is of great significance to find the specific signal pathway leading to the occurrence of NAFLD. Intriguingly, $\mathrm{C} 3 \mathrm{aR}$ was indicated to be a remarkable gene closely related to obesity and potential insulin resistance in the mice model intercrossed among different strains by integrated genomic analysis (92). On this base, it is speculated to be a very promising treatment through targeting $\mathrm{C} 3 \mathrm{a} / \mathrm{C} 3 \mathrm{aR}$ in the pathogenesis of NAFLD. So far, researchers have designed a variety of small molecule antagonists for $\mathrm{C} 3 \mathrm{a} / \mathrm{C} 3 \mathrm{aR}$ signaling pathway and verified their pharmacological effects. For example, a series of diaminoisoindoline compounds can play a significant role as $\mathrm{C} 3 \mathrm{a}$ antagonist at the micromolar level (93). A new oral selective antagonist of $\mathrm{C} 3 \mathrm{a}$ receptor, discovered by heterocyclic hinge control conformation, can significantly block the recruitment and activation of macrophages and neutrophils and then play the role of inhibiting the expression of inflammatory mediators (94). Also known is FLTChaAR (IC50 $240 \mathrm{nM}, \mathrm{Ca} 2+$, macrophages), a significant hexapeptide C3a antagonist, which provide an important reference for the coming antagonist design (95). As $\mathrm{C} 3 \mathrm{aR}$ antagonist obtained through high-throughput screening, Sb290157 is thought as the most promising drug for the treatment of metabolic syndrome including NAFLD in the clinical future $(88,96)$. In the obese rat models fed by high carbohydrate and saturated fat diet, SB 290157 can attenuate the inflammatory response by mainly controlling macrophages into adipose or liver tissue (97), which significantly reduce the obesity and body weight by effectively improving liver metabolism (27). Subsequently, it was further confirmed that the IC50s of sb290157 were $27.7 \mathrm{~nm}$ in RBL-C3aR cells and $28 \mathrm{~nm}$ human neutrophils, respectively. Most importantly, sb290157 is found to acts selectively on C3aR not C5aR or other six chemotactic G protein coupled receptors, which indicates very potential effect in the clinical application (96).

Recent evidence has elucidated $\mathrm{C} 3$ as a potent lipogenic hormone in the pathogenesis of NAFLD according to preclinical and translational evidence. Theoretically, initial discussions primarily relied on considerations of C3 deficiency which often leads to a broader range of susceptibilities to infections. As a matter of factor, it can be effectively avoided by developing therapies targeting $\mathrm{C} 3 \mathrm{a} / \mathrm{C} 3 \mathrm{aR}$, which participates in inflammatory responses such as anti COVID-19 and anti-HCC treatment (97-102). Complement C3 activation may interfere with NAFLD with at least two distinct mechanisms by enhancing adipose tissue inflammation via the local engagement of $\mathrm{C} 3 \mathrm{a}$ and $\mathrm{C} 5 \mathrm{a}$ receptors as well as by providing the substrate for the conversion of C3a into ASP that may exerts its effects systemically (103). Regretfully, no clinical registered trial is found to target $\mathrm{C} 3 \mathrm{a}$ or C3aR in NASH therapy so far. Our previous studies have shown that $\mathrm{C} 3 \mathrm{a} / \mathrm{C} 3 \mathrm{aR}$ participates in the pathogenesis of 
NASH even fibrosis by regulating various signaling pathways and mentioned the protective function in the $\mathrm{C}_{3} \mathrm{aR}^{-/-}$mice model (28). Therefore, in-depth investigations and awareness of the roles of $\mathrm{C} 3 \mathrm{a} / \mathrm{C} 3 \mathrm{aR}$ in NASH are urgently needed that will lead to a further expansion of potential indications for complement treatments in the future.

Traditionally, C3a/C3aR signaling axis plays a proinflammatory role in the pathogenesis of NAFLD. However, recent studies have found that in the early stage of NAFLD, C3a plays an anti-inflammatory role by preventing neutrophils from accumulating in liver tissue (58). In fact, whether C3a is pro-inflammatory or anti-inflammatory is not mutually exclusive in the pathogenesis of NAFLD, but depends on the balance between pro-inflammatory and anti-inflammatory effects of $\mathrm{C} 3 \mathrm{a}$, which determines the final outcome of the disease (Figure 3). For example, C3a plays a pro-inflammatory role in the NASH stage of NAFLD by activating Kupffer cells under the effect of neutrophil elastase. If neutrophils were deleted at that time, the activation of Kupffer cells was significantly delayed (104). Therefore, the dual role of C3a/C3aR signaling axis should be considered for the rational designing therapeutic strategies targeting $\mathrm{C} 3 \mathrm{a} / \mathrm{C} 3 \mathrm{aR}$ in the effective treatment of NAFLD.

\section{CONCLUSION}

Complement system is one of the most important innate immune barriers in the body, among which complement C3 is the

\section{REFERENCES}

1. Mantovani A. Nonalcoholic fatty liver disease (NAFLD) and risk of cardiac arrhythmias: a new aspect of the liver-heart axis. JClin Transl Hepatol. (2017) 5:134-41. doi: 10.14218/JCTH.2017.00005

2. Zhou F, Zhou J, Wang W, Zhang XJ, Ji YX, Zhang P, et al. Unexpected rapid increase in the burden of NAFLD in China from 2008 to 2018: a systematic review and meta-Analysis. Hepatology. (2019) 70:111933. doi: 10.1002/hep.30702

3. Younossi Z, Anstee QM, Marietti M, Hardy T, Henry L, Eslam M, et al. Global burden of NAFLD and NASH: trends, predictions, risk factors and prevention. Nat Rev Gastroenterol Hepatol. (2018) 15:1120. doi: 10.1038/nrgastro.2017.109

4. Braun HA, Faasse SA, Vos MB. Advances in pediatric fatty liver disease: pathogenesis, diagnosis, and treatment. Gastroenterol Clin North Am. (2018) 47:949-68. doi: 10.1016/j.gtc.2018.07.016

5. Lung $T$, Sakem B, Risch L, Würzner R, Colucci G, Cerny A, et al. The complement system in liver diseases: evidence-based approach and therapeutic options. J Transl Autoimmun. (2019) 2:100017. doi: 10.1016/j.jtauto.2019.100017

6. Sharma M, Mitnala S, Vishnubhotla RK, Mukherjee R, Reddy DN, Rao PN. The riddle of nonalcoholic fatty liver disease: progression from nonalcoholic fatty liver to nonalcoholic steatohepatitis. J Clin Exp Hepatol. (2015) 5:14758. doi: 10.1016/j.jceh.2015.02.002

7. Ricklin D, Hajishengallis G, Yang K, Lambris JD. Complement: a key system for immune surveillance and homeostasis. Nat Immunol. (2010) 11:78597. doi: 10.1038/ni.1923

8. Reis ES, Mastellos DC, Hajishengallis G, Lambris JD. New insights into the immune functions of complement. Nat Rev Immunol. (2019) 19:50316. doi: 10.1038/s41577-019-0168-x

9. Thorgersen EB, Barratt-Due A, Haugaa H, Harboe M, Pischke SE, Nilsson $\mathrm{PH}$, et al. The role of complement in liver injury, regeneration, critical component in complement cascade activation. Clinically, increased epidemiological evidence has shown that C3 is closely related to the pathogenesis of NAFLD. Serum fatty acids, adipose tissue-derived cytokines and gut derived endotoxin can take part in complement activation. After complement activation, C3 interacts with different types of liver innate immune cells, and ultimately participates in the pathogenesis of NAFLD. C3a is an important derivative from $\mathrm{C} 3$ when complement cascades are activated. Accumulating studies indicate that C3a plays an important role in the pathogenesis of NAFLD by interacting with its receptor $\mathrm{C} 3 \mathrm{aR}$. Targeted inhibition of $\mathrm{C} 3 \mathrm{aR}$ activation is a potential strategy for the prevention and treatment of NAFLD. Although SB 290157 is an effective and selective C3aR antagonist in some experimental animal models, the preclinical and clinical evidence of SB 290157 needs to be explored to prevent dietary obesity, metabolic dysfunction and NAFLD in the coming future.

\section{AUTHOR CONTRIBUTIONS}

$\mathrm{JH}$ and $\mathrm{XZ}$ were involved in study design and drafted the paper. $\mathrm{XZ}$ supervised and reviewed the paper. All authors contributed to the article and approved the submitted version.

\section{FUNDING}

The project was supported by a grant from National Natural Science Foundation of China (No. 81970512). and transplantation. Hepatology. (2019) 70:725-36. doi: 10.1002/hep. 30508

10. Wagner E, Frank MM. Therapeutic potential of complement modulation. Nat Rev Drug Discov. (2010) 9:43-56. doi: 10.1038/nrd3011

11. Ju C, Tacke F. Hepatic macrophages in homeostasis and liver diseases: from pathogenesis to novel therapeutic strategies. Cell Mol Immunol. (2016) 13:316-27. doi: 10.1038/cmi.2015.104

12. Yesilova Z, Ozata M, Oktenli C, Bagci S, Ozcan A, Sanisoglu SY, et al. Increased acylation stimulating protein concentrations in nonalcoholic fatty liver disease are associated with insulin resistance. Am J Gastroenterol. (2005) 100:842-9. doi: 10.1111/j.1572-0241.2005.40838.x

13. Wlazlo N, van Greevenbroek MM, Ferreira I, Jansen EH, Feskens EJ, van der Kallen CJ, et al. Activated complement factor 3 is associated with liver fat and liver enzymes: the CODAM study. Eur J Clin Invest. (2013) 43:679-88. doi: 10.1111/eci.12093

14. Jia Q, Li C, Xia Y, Zhang Q, Wu H, Du H, et al. Association between complement $\mathrm{C} 3$ and prevalence of fatty liver disease in an adult population: a cross-sectional study from the tianjin chronic low-grade systemic inflammation and health (TCLSIHealth) cohort study. PLoS ONE. (2015) 10:e122026. doi: 10.1371/journal.pone.0122026

15. Xu C, Chen Y, Xu L, Miao M, Li Y, Yu C. Serum complement C3 levels are associated with nonalcoholic fatty liver disease independently of metabolic features in Chinese population. Sci Rep. (2016) 6:23279. doi: 10.1038/srep23279

16. Rensen SS, Slaats Y, Driessen A, Peutz-Kootstra CJ, Nijhuis J, Steffensen R, et al. Activation of the complement system in human nonalcoholic fatty liver disease. Hepatology. (2009) 50:1809-1817. doi: 10.1002/hep.23228

17. Pan B, Wan X, Ma M, Cao C. Complement C3 and nonalcoholic fatty liver disease in chronic kidney disease patients: a pilot study. Kidney Blood Press Res. (2020) 45:61-9. doi: 10.1159/000504172

18. Ursini F, Russo E, Mauro D, Abenavoli L, Ammerata G, Serrao A, et al. Complement $\mathrm{C} 3$ and fatty liver disease in rheumatoid arthritis 
patients: a cross-sectional study. Eur J Clin Invest. (2017) 47:72835. doi: $10.1111 /$ eci. 12798

19. Himoto T, Hirakawa E, Fujita K, Sakamoto T, Nomura T, Morishita A, et al. Complement component 3 as a surrogate hallmark for metabolic abnormalities in patients with chronic hepatitis C. Ann Clin Lab Sci. (2019) 49:79-88.

20. Vaisar T, Pennathur S, Green PS, Gharib SA, Hoofnagle AN, Cheung MC, et al. Shotgun proteomics implicates protease inhibition and complement activation in the antiinflammatory properties of HDL. J Clin Invest. (2007) 117:746-56. doi: 10.1172/JCI26206

21. Choy LN, Rosen BS, Spiegelman BM. Adipsin and an endogenous pathway of complement from adipose cells. J Biol Chem. (1992) 267:1273641 doi: 10.1016/S0021-9258(18)42338-1

22. Persson L, Borén J, Robertson AK, Wallenius V, Hansson GK, Pekna M. Lack of complement factor C3, but not factor B, increases hyperlipidemia and atherosclerosis in apolipoprotein E-/- low-density lipoprotein receptor-/- mice. Arterioscler Thromb Vasc Biol. (2004) 24:1062-7. doi: 10.1161/01.ATV.0000127302.24266.40

23. Brunt EM. Pathology of nonalcoholic fatty liver disease. Nat Rev Gastroenterol Hepatol. (2010) 7:195-203. doi: 10.1038/nrgastro.2010.21

24. Meli R., Raso M, Calignano G. Role of innate immune response in nonalcoholic fatty liver disease: metabolic complications and therapeutic tools. Front Immunol. (2014) 5:177. doi: 10.3389/fimmu.2014.00177

25. Malhi H, Gores GJ. Molecular mechanisms of lipotoxicity in nonalcoholic fatty liver disease. Semin Liver Dis. (2008) 28:360-9. doi: 10.1055/s-0028-1091980

26. Cianflone K, Xia Z, Chen LY. Critical review of acylation-stimulating protein physiology in humans and rodents. Biochem Biophys Acta. (2003) 1609:12743. doi: 10.1016/S0005-2736(02)00686-7

27. Lim J, Iyer A, Suen JY, Seow V, Reid RC, Brown L, et al. C5aR and $\mathrm{C} 3 \mathrm{aR}$ antagonists each inhibit diet-induced obesity, metabolic dysfunction, and adipocyte and macrophage signaling. FASEB J. (2013) 27:82231. doi: 10.1096/fj.12-220582

28. Han J, Zhang X, Lau JK, Fu K, Lau HC, Xu W, et al. Bone marrow-derived macrophage contributes to fibrosing steatohepatitis through activating hepatic stellate cells. J Pathol. (2019) 248:488-500. doi: 10.1002/path.5275

29. Ricklin D, Reis ES, Mastellos DC, Gros P, Lambris JD. Complement component C3 - the "Swiss Army Knife" of innate immunity and host defense. Immunol Rev. (2016) 274:33-58 doi: 10.1111/imr.12500

30. Markiewski MM, Lambris JD. The role of complement in inflammatory diseases from behind the scenes into the spotlight. Am J Pathol. (2007) 171:715-27. doi: 10.2353/ajpath.2007.070166

31. Gerard N P, Gerard C. Complement in allergy and asthma. Curr Opin Immunol. (2002) 14:705-8. doi: 10.1016/S0952-7915(02)00410-7

32. Mizutani N, Nabe T, Yoshino S. Complement C3a regulates late asthmatic response and airway hyperresponsiveness in mice. J Immunol. (2009) 183:4039-46. doi: 10.4049/jimmunol.0901468

33. Hutamekalin P, Takeda K, Tani M, Tsuga Y, Ogawa N, Mizutani N, et al. Effect of the C3a-receptor antagonist SB 290157 on anti-OVA polyclonal antibody-induced arthritis. J Pharmacol Sci. (2010) 112:5663. doi: 10.1254/jphs.09180FP

34. Kildsgaard J, Hollmann TJ, Matthews KW, Bian K, Murad F, Wetsel RA. Cutting edge: targeted disruption of the $\mathrm{C} 3$ a receptor gene demonstrates a novel protective anti-inflammatory role for C3a in endotoxinshock. $J$ Immunol. (2000) 165:5406-9. doi: 10.4049/jimmunol.165.10.5406

35. Jacob A, Bao L, Brorson J, Quigg RJ, Alexander JJ. C3aR inhibition reduces neurodegeneration in experimental lupus. Lupus. (2010) 19:7382. doi: 10.1177/0961203309348978

36. Mamane Y, Chung Chan C, Lavallee G, Morin N, Xu LJ, Huang J, et al. The C3a anaphylatoxin receptor is a key mediator of insulin resistance and functions by modulating adipose tissue macrophage infiltration and activation. Diabetes. (2009) 58:2006-17. doi: 10.2337/db09-0323

37. Proctor LM, Arumugam TV, Shiels I, Reid RC, Fairlie DP, Taylor SM. Comparative anti-inflammatory activities of antagonists to C3a C5a receptors in a rat model of intestinal ischaemia/reperfusion injury. $\mathrm{Br} \mathrm{J}$ Pharmacol. (2004) 142:756-64. doi: 10.1038/sj.bjp.0705819

38. Chazin WJ, Hugli TE, Wright PE. 1H NMR studies of human $\mathrm{C} 3 \mathrm{a}$ anaphylatoxin in solution: sequential resonance assignments, secondary structure, and global fold. Biochemistry.

(1988) 27:9139-48. doi: 10.1021/bi00426a011

39. Hugli TE, Erickson BW. Synthetic peptides with the biological activities and specificity of human C3a anaphylatoxin. Proc Natl Acad Sci USA. (1977) 74:1826-30. doi: 10.1073/pnas.74.5.1826

40. Chang JY, Lin CC, Salamanca S, Pangburn MK, Wetsel RA. Denaturation and unfolding of human anaphylatoxin C3a: an unusually low covalent stability of its native disulfide bonds. Arch Biochem Biophys. (2008) 480:10410. doi: 10.1016/j.abb.2008.09.013

41. Langkabel P, Zwirner J, Oppermann M. Ligand-induced phosphorylation of anaphylatoxin receptors $\mathrm{C} 3 \mathrm{aR}$ and $\mathrm{C} 5 \mathrm{aR}$ is mediated by $\mathrm{G}$ proteincoupled receptor kinases. Eur J Immunol. (1999) 29:3035-46. doi: 10.1002/ (SICI)1521-4141(199909)29:09<3035::AID-IMMU3035>3.0.CO;2-Z

42. Monsinjon T, Gasque P, Chan P, Ischenko A, Brady JJ, Fontaine MC. Regulation by complement $\mathrm{C} 3 \mathrm{a}$ and $\mathrm{C} 5 \mathrm{a}$ anaphylatoxins of cytokine production in human umbilical vein endothelial cells. FASEB J. (2003) 17:1003-14. doi: 10.1096/fj.02-0737com

43. Sayah S, Jauneau C, Patte C, Tonon MC, Vaudry H, Fontaine M. Two different transduction pathways are activated by $\mathrm{C} 3 \mathrm{a}$ and $\mathrm{C} 5 \mathrm{a}$ anaphylatoxins on astrocytes. Brain Res Mol Brain Res. (2003) 112:5360. doi: 10.1016/S0169-328X(03)00046-9

44. Shinjyo N, Stahlberg A, Dragunow M, Pekny M, Pekna M. Complementderived anaphylatoxin C3a regulates in vitro differentiation and migration of neural progenitor cells. Stem Cells. (2009) 27:2824-32. doi: 10.1002/stem.225

45. Ruan B, Li X, Winkler A, Cunningham KM, Kuai J, Greco RM, et al. Complement C3a,CpG oligos, and DNA/C3a complex stimulate IFN-a production in a receptor for advanced glycation end product-dependent manner. J Immunol. (2010) 185:4213-22. doi: 10.4049/jimmunol.1000863

46. Hannedouche S, Beck V, Leighton-Davies J, Beibel M, Roma G, Oakeley EJ, et al. Identification of the C3a receptor (C3aR1) as the target of the VGFderived peptide TLQP-21 in rodent cells. J Biol Chem. (2013) 288:2743443. doi: 10.1074/jbc.M113.497214

47. Cero C, Vostrikov VV, Verardi R, Severini C, Gopinath T, Braun PD, et al. The TLQP-21 peptide activates the G-protein-coupled receptor C3aR1 via a folding-upon-binding mechanism. Structure. (2014) 22:174453. doi: 10.1016/j.str.2014.10.001

48. Xie J, Me’ndez J, Me’ndez-Valenzuela V, Aguilar-Hernández MM. Cellular signaling of the receptor for advanced glycation end products (RAGE). Cell Signal. (2013) 25:2185-97. doi: 10.1016/j.cellsig.2013.06.013

49. Kazankov K, Jørgensen SMD, Thomsen KL, Møller HJ, Vilstrup H, George $\mathrm{J}$, et al. The role of macrophages in nonalcoholic fatty liver disease and nonalcoholic steatohepatitis. Nat Rev Gastroenterol Hepatol. (2019) 16:14559. doi: 10.1038/s41575-018-0082-X

50. Devisscher L, Verhelst X, Colle I, Van Vlierberghe H, Geerts A. The role of macrophages in obesity-driven chronic liver disease. J Leukocyte Biolog. (2016) 99:693-8. doi: 10.1189/jlb.5RU0116-016R

51. Baffy G. Kupffer cells in non-alcoholic fatty liver diseases: the emerging view. J Hepatol. (2009) 51:212-23. doi: 10.1016/j.jhep.2009.03.008

52. Marra F, Tacke F. Roles for chemokines in liver disease. Gastroenterology. (2014) 147:577-94. doi: 10.1053/j.gastro.2014.06.043

53. Miura K, Yang L, van Rooijen N, Ohnishi H, Seki E. Hepatic recruitment of macrophages promotes nonalcoholic steatohepatitis through CCR2. Am J Physiol Gastrointest Liver Physiol. (2012) 302:G1310321. doi: 10.1152/ajpgi.00365.2011

54. Tosello-Trampont AC1, Landes SG, Nguyen V, Novobrantseva TI, Hahn YS. Kuppfer cells trigger nonalcoholic steatohepatitis development in dietinduced mouse model through tumor necrosis factor-a production. J Bio Chem. (2012) 287:40161-72. doi: 10.1074/jbc.M112.417014

55. Duffield JS, Forbes SJ, Constandinou CM, Clay S, Partolina M, Vuthoori $S$, et al. Selective depletion of macrophages reveals distinct, opposing roles during liver injury and repair. J Clin Invest. (2005) 115:5665. doi: 10.1172/JCI200522675

56. Sunami Y, Leithäuser F, Gul S, Fiedler K, Güldiken N, Espenlaub S, et al. Hepatic activation of $\mathrm{IKK} / \mathrm{NF \kappa B}$ signaling induces liver fibrosis via macrophage-mediated chronic inflammation. Hepatology. (2012) 56:111728. doi: 10.1002/hep. 25711

57. Banda NK, Hyatt S, Antonioli AH, White JT, Glogowska M, Takahashi K, et al. Role of $\mathrm{C} 3 \mathrm{a}$ receptors, $\mathrm{C} 5 \mathrm{a}$ receptors, and complement protein $\mathrm{C} 6$ 
deficiency in collagen antibody-induced arthritis in mice. J Immunol. (2012) 188:1469-78. doi: 10.4049/jimmunol.1102310

58. Coulthard LG, Woodruff TM. Is the complement activation product C3a a proinflammatory molecule? Re-evaluating the evidence and the myth. $J$ Immunol. (2015) 194:3542-48. doi: 10.4049/jimmunol.1403068

59. Takabayashi T, Vannier E, Clark BD, Margolis NH, Dinarello CA, Burke JF, et al. A new biologic role for C3a and C3a desArg: regulation of TNF-alpha and IL-1 beta synthesis. J Immunol. (1996) 156:3455-60.

60. Takabayashi T, Vannier E, Burke JF, Tompkins RG, Gelfand JA, Clark $\mathrm{BD}$. Both $\mathrm{C} 3 \mathrm{a}$ and $\mathrm{C} 3 \mathrm{a}(\mathrm{des} A \mathrm{rg})$ regulate interleukin-6 synthesis in human peripheral blood mononuclear cells. J Infect Dis. (1998) 177:16228. doi: $10.1086 / 515316$

61. Monsinjon T, Gasque P, Ischenko A, Fontaine M. C3a binds to the seven transmembrane anaphylatoxin receptor expressed by epithelial cells and triggers the production of IL-8. FEBS Lett. (2001) 487:33946. doi: 10.1016/S0014-5793(00)02320-6

62. Fischer WH, Jagels MA, Hugli TE. Regulation of IL-6 synthesis in human peripheral blood mononuclear cells by C3a and C3a (desArg). J. Immunol. (1999) 162:453-9.

63. Asgari E, Le Friec G, Yamamoto H, Perucha E, Sacks SS, Köhl J, et al. C3a modulates IL-1b secretion in human monocytes by regulating ATP efflux and subsequent NLRP3 inflammasome activation. Blood. (2013) 122:347381. doi: 10.1182/blood-2013-05-502229

64. Malik A, Thanekar U, Amarachintha S, Mourya R, Nalluri S, Bondoc A, et al. "Complimenting the complement": mechanistic insights and opportunities for therapeutics in hepatocellular carcinoma. Front Oncol. (2021) 10:62770131. doi: $10.3389 /$ fonc. 2020.627701

65. Xu Y, Huang Y, Xu W, Zheng X, Yi X, Huang L, et al. Activated hepatic stellate cells (HSCs) exert immunosuppressive effects in hepatocellular carcinoma by producing complement C3. Onco Targets Ther. (2020) 13:1497-505. doi: 10.2147/OTT.S234920

66. Weiskirchen R, Tacke F. Cellular and molecular functions of hepatic stellate cells in inflammatory responses and liver immunology. Hepatobiliary Surg Nutr. (2014) 3:344-63. doi: 10.3978/j.issn.2304-3881.2014.11.03

67. Maher JJ, Leon P, Ryan JC. Beyond insulin resistance: innate immunity in nonalcoholic steatohepatitis. Hepatology. (2008) 48:670-8. doi: 10.1002/hep.22399

68. Hammerich L, Heymann F, Tacke F. Role of IL-17 and Th17 cells in liver diseases. Clin Dev Immunol. (2011) 2011:345803. doi: 10.1155/2011/345803

69. Tang Y, Bian Z, Zhao L, Liu Y, Liang S, Wang Q, et al. Interleukin-17 exacerbates hepatic steatosis and inflammation in non-alcoholic fatty liver disease. Clin Exp Immunol. (2011) 166:281-90. doi: 10.1111/j.1365-2249.2011.04471.x

70. Rau M, Schilling AK, Meertens J, Hering I, Weiss J, Jurowich C, et al. Progression from nonalcoholic fatty liver to nonalcoholic steatohepatitis is marked by a higher frequency of Th17 cells in the liver and an increased Th17/resting regulatory $\mathrm{T}$ cell ratio in peripheral blood and in the liver. $J$ Immunol. (2016) 196:97-105. doi: 10.4049/jimmunol.1501175

71. Li J, Qiu SJ, She WM, Wang FP, Gao H, Li L, et al. Significance of the balance between regulatory $\mathrm{T}$ (Treg) and $\mathrm{T}$ helper 17 (Th17) cells during hepatitis B virus related liver fibrosis. PLoS ONE. (2012) 7:e39307. doi: 10.1371/journal.pone.0039307

72. Liu Y, She W, Wang F, Li J, Wang J, Jiang W. 3, 3'-diindolylmethane alleviates steatosis and the progression of NASH partly through shifting the imbalance of Treg/Th17 cells to Treg dominance. Int Immunopharmacol. (2014) 23:489-98. doi: 10.1016/j.intimp.2014.09.024

73. Lim H, Kim Y, Drouin S, Mueller-Ortiz S, Yun K, Morschl E, et al. Negative regulation of pulmonary Th17 responses by C3a anaphylatoxin during allergic inflammation in mice. PLoS ONE. (2012) 7:e52666. doi: 10.1371/journal.pone.0052666

74. Drouin S, Corry M, Hollman T, Brodeur S, Bryce P, Lu B, et al. Absence of the complement anaphylatoxin $\mathrm{C} 3 \mathrm{a}$ receptor suppresses Th2 effector functions in a murine model of pulmonary allergy. J Immunol. (2002) 169:5926-33. doi: 10.4049/jimmunol.169.10.5926

75. Martin U, Bock D, Arseniev L, Tornetta MA, Ames RS, Bautsch $\mathrm{W}$, et al. The human C3a receptor is expressed on neutrophils and monocytes, but not on B or T lymphocytes. J Exp Med. (1997) 186:199207. doi: $10.1084 /$ jem.186.2.199
76. Strainic M, Shevach E, An F, Lin F, Medof ME. Absence of signaling into $\mathrm{CD} 4+$ cells via $\mathrm{C} 3 \mathrm{aR}$ and $\mathrm{C} 5 \mathrm{aR}$ enables autoinductive TGF-b1 signaling and induction of Foxp3+ regulatory T cells. Nat Immunol. (2013) 14:162171. doi: 10.1038/ni.2499

77. Liszewski MK, Kolev M, Le Friec G, Leung M, Bertram PG, Fara AF, et al. Intracellular complement activation sustains $\mathrm{T}$ cell homeostasis and mediates effector differentiation. Immunity. (2013) 39:1143-57. doi: 10.1016/j.immuni.2013.10.018

78. Kwan W, van der Touw W, Paz-Artal E, Li MO, Heeger PS. Signaling through $\mathrm{C} 5 \mathrm{a}$ receptor and $\mathrm{C} 3 \mathrm{a}$ receptor diminishes function of murine natural regulatory T cells. J. Exp. Med. (2013) 210:257-68. doi: 10.1084/jem.20121525

79. Strainic M, Liu J, Huang D, An F, Lalli PN, Muqim N, et al. Locally produced complement fragments $\mathrm{C} 5 \mathrm{a}$ and $\mathrm{C} 3 \mathrm{a}$ provide both costimulatory and survival signals to naive CD4+ T cells. Immunity. (2008) 28:42535. doi: 10.1016/j.immuni.2008.02.001

80. Kawamoto S, Yalcindag A, Laouini D, Brodeur S, Bryce P, Lu B, et al. The anaphylatoxin $\mathrm{C} 3 \mathrm{a}$ downregulates the $\mathrm{Th} 2$ response to epicutaneously introduced antigen. J Clin Invest. (2004) 114:399-407. doi: 10.1172/JCI200419082

81. Nati M, Haddad D, Birkenfeld AL, Koch CA, Chavakis T, Chatzigeorgiou A. The role of immune cells in metabolism-related liver inflammation and development of non-alcoholic steatohepatitis (NASH). Rev Endocr Metab Disord. (2016) 17:29-39. doi: 10.1007/s11154-016-9339-2

82. Cai JJ, Zhang XJ, Li HL. The role of innate immune cells in nonalcoholic steatohepatitis. Hepatology. (2019) 70:1026-37. doi: 10.1002/hep.30506

83. Ou R, Liu J, Lv M, Wang J, Wang J, Zhu L, et al. Neutrophil depletion improves diet-induced non-alcoholic fatty liver disease in mice. Endocrine. (2017) 57:72-82. doi: 10.1007/s12020-017-1323-4

84. Yilmaz H, Yalcin KS, Namuslu M, Celik HT, Sozen M, Inan O, et al. Neutrophil-lymphocyte ratio (NLR) could be better predictor than C-reactive protein (CRP) for liver fibrosis in non-alcoholic steatohepatitis(NASH). Ann Clin Lab Sci. (2015) 45:278-86.

85. Khoury T, Mari A, Nseir W, Kadah A, Sbeit W, Mahamid M. Neutrophil-tolymphocyte ratio is independently associated with inflammatory activity and fibrosis grade in nonalcoholic fatty liver disease. Eur J Gastroenterol Hepatol. (2019) 31:1110-5. doi: 10.1097/MEG.0000000000001393

86. Hatting M, Tacke F. From NAFLD to HCC: is IL-17 the crucial link? Hepatology. (2017) 65:739-41. doi: 10.1002/hep.28934

87. Alkhouri N, Morris-Stiff G, Campbell C, Lopez R, Tamimi TA, Yerian L, et al. Neutrophil to lymphocyte ratio: a new marker for predicting steatohepatitis and fibrosis in patients with nonalcoholic fatty liver disease. Liver Int. (2012) 32:297-302. doi: 10.1111/j.1478-3231.2011.02639.x

88. Bettelli E, Carrier Y, Gao W, Korn T, Strom TB, Oukka M, et al. Reciprocal developmental pathways for the generation of pathogenic effector TH17 and regulatory T cells. Nature. (2006) 441:235-8. doi: 10.1038/nature04753

89. Geginat J, Paroni M, Maglie S, Alfen JS, Kastirr I, Gruarin P, et al. Plasticity of human CD4 T cell subsets. Front Immunol. (2014) 5:630. doi: 10.3389/fimmu.2014.00630

90. Castera L, Friedrich-Rust M, Loomba R. Noninvasive assessment of liver disease in patients with nonalcoholic fatty liver disease. Gastroenterology. (2019) 156:1264-81.e4. doi: 10.1053/j.gastro.2018.12.036

91. Pirola CJ, Sookoian S. Multiomics biomarkers for the prediction of nonalcoholic fatty liver disease severity. World J Gastroenterol. (2018) 24:1601-15. doi: 10.3748/wjg.v24.i15.1601

92. Schadt EE, Lamb J, Yang X, Zhu J, Edwards S, Guhathakurta D, et al. An integrative genomics approach to infer causal associations between gene expression and disease. Nat Genet. (2005) 37:710-7. doi: 10.1038/ng1589

93. Grant EB, Guiadeen D, Singer M, Argentieri D, Hlasta DJ, Wachter M. Design, synthesis, and biological activity of diiminoisoindolines as complement component 3a antagonists. Bioorg Med Chem Lett. (2001) 11:2817-20. doi: 10.1016/S0960-894X(01)00522-4

94. Lohman RJ, Hamidon JK, Reid R C, Rowley JA, Yau MK, Halili MA, et al. Exploiting a novel conformational switch to control innate immunity mediated by complement protein C3a. Nat Commun. (2017) 8:35166. doi: 10.1038/s41467-017-00414-w

95. Scully CC, Blakeney JS, Singh R, Hoang HN, Abbenante G, Reid RC, et al. Selective hexapeptide agonists and antagonists for human complement 
C3a receptor. J Med Chem. (2010) 53:4938-48. doi: 10.1021/jm10 03705

96. Ames RS, Lee D, Foley JJ, Jurewicz AJ, Tornetta MA, Bautsch W, et al. Identification of a selective nonpeptide antagonist of the anaphylatoxin C3a receptor that demonstrates anti-inflammatory activity in animal models. $J$ Immunol. (2001) 166:6341-8. doi: 10.4049/jimmunol.166.10.6341

97. Ajona D, Ortiz-Espinosa S, Pio R. Complement anaphylatoxins C3a and C5a: emerging roles in cancer progression and treatment. Semin Cell Dev Biol. (2019) 85:153-63. doi: 10.1016/j.semcdb.2017.11.023

98. Pio R, Ajona D, Lambris JD. Complement inhibition in cancer therapy. Semin Immunol. (2013) 25:54-64. doi: 10.1016/j.smim.2013.04.001

99. Sinkovits G, Mezo B, Réti M, Müller V, Iványi Z, Gál J, et al. Complement overactivation and consumption predicts in-hospital mortality in SARS-CoV-2 infection. Front Immunol. (2021) 12:663187-210. doi: 10.3389/fimmu.2021.663187

100. Mastellos DC, Pires da Silva BGP, Fonseca BAL, Fonseca NP, AuxiliadoraMartins M, Mastaglio S, et al. Complement C3 vs C5 inhibition in severe COVID-19: early clinical findings reveal differential biological efficacy. Clin Immunol. (2020) 220:108598-608. doi: 10.1016/j.clim.2020.108598

101. Ursini F, Abenavoli L. The emerging role of complement C3 as a biomarker of insulin resistance and cardiometabolic diseases: preclinical and clinical evidence. Rev Recent Clin Trials. (2018) 13:61-8. doi: 10.2174/1574887112666171128134552

102. Mastaglio S, Ruggeri A, Risitano AM, Angelillo P, Yancopoulou D, Mastellos DC, et al. The first case of COVID-19 treated with the complement C3 inhibitor AMY-101. Clin Immunol. (2020) 215:1084504. doi: 10.1016/j.clim.2020.108450
103. Yuan M, Konstantopoulos N, Lee J, Hansen L, Li ZW, Karin M, et al. Reversal of obesity- and diet-induced insulin resistance with salicylates or targeted disruption of Ikkbeta. Science. (2001) 293:16737. doi: 10.1126/science.1061620

104. Zang S, Wang L, Ma X, Zhu G, Zhuang Z, Xun Y, et al. Neutrophils play a crucial role in the early stage of nonalcoholic steatohepatitis via neutrophil elastase in mice. Cell Biochem Biophys. (2015) 73:479-87. doi: 10.1007/s12013-0150682-9

Conflict of Interest: The authors declare that the research was conducted in the absence of any commercial or financial relationships that could be construed as a potential conflict of interest.

Publisher's Note: All claims expressed in this article are solely those of the authors and do not necessarily represent those of their affiliated organizations, or those of the publisher, the editors and the reviewers. Any product that may be evaluated in this article, or claim that may be made by its manufacturer, is not guaranteed or endorsed by the publisher.

Copyright (c) 2021 Han and Zhang. This is an open-access article distributed under the terms of the Creative Commons Attribution License (CC BY). The use, distribution or reproduction in other forums is permitted, provided the original author(s) and the copyright owner(s) are credited and that the original publication in this journal is cited, in accordance with accepted academic practice. No use, distribution or reproduction is permitted which does not comply with these terms. 